\title{
Preconcentration of ultratrace rare earth elements in seawater with 8-hydroxyquinoline immobilized polyacrylonitrile hollow fiber membrane for determination by inductively coupled plasma mass spectrometry
}

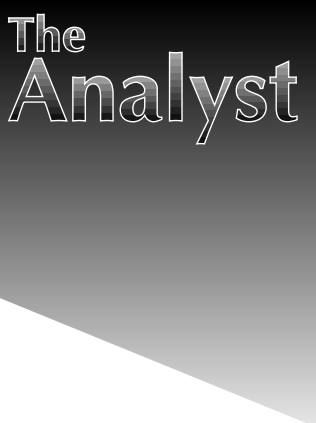

\author{
Bei Wen, Xiao-quan Shan* and Shu-guang Xu \\ Research Center for Eco-Environmental Sciences, Chinese Academy of Sciences, P.O. Box \\ 2871, Beijing 100085, China. E-mail: Xiaoquan@mail.rcees.ac.cn; Fax: 861062923563
}

Received 18th December 1998, Accepted 15th February 1999

\begin{abstract}
8-Hydroxyquinoline immobilized on polyacrylonitrile hollow fiber membrane was synthesized and used for the preconcentration of rare earth elements (REEs) and the separation of the matrix in seawater prior to their determination by inductively coupled plasma mass spectrometry (ICP-MS). Both the capacity and chemical stability of the modified polyacrylonitrile hollow fiber membrane have been evaluated. The optimum experimental conditions, such as $\mathrm{pH}$, sample flow rate, volume of eluents, were investigated. The concentration of REEs in seawater and the separation of the matrix components can be achieved with a concentration factor of at least 300 times. The recommended method has been applied for the concentration and determination of REEs in coastal seawater. Results indicated that the recovery of REEs ranged from $91 \%$ to $107 \%$, and the relative standard deviations were found to be less than 5\%. A comparison was made between the REE levels determined by this method and the literature reports, and a reasonable agreement was obtained.
\end{abstract}

With the widespread application of rare earth elements (REEs) in industry, agriculture, forestry and animal husbandry, much attention is now being paid to the study of REEs in the environment. However, the determination of REEs in seawater has always been a difficult task. The main restriction comes from the extremely low levels of REEs, which are below the detection limit of many instruments. Inductively coupled plasma mass spectrometry (ICP-MS) occupies an invaluable position in the modern analytical laboratory due to its excellent sensitivity, precision and accuracy. Although it is especially suitable for trace muti-element determination and is applicable to a wide range of samples, its application to the analysis of saline water remains quite limited, mainly due to the high matrix concentration (approximately 3.5\%) present in seawater, which prohibits its direct analysis by ICP-MS owing to the obvious problems of salt deposition on the torch, sampling interface, or ion lenses. Therefore, the development of a preconcentration technique is an important consideration for seawater analysis.

A lot of preconcentration techniques have been proposed for the determination of metals in various environmental samples. Compared with the more traditional liquid-liquid extraction methods, solid-phase techniques have become increasingly popular. It is recognized that 8-hydroxyquinoline is a well characterized organic chelation ligand, which can form covalent compounds with over 60 metal ions under controlled $\mathrm{pH}$ conditions, and its preference for transition and heavy metal cations over alkali and alkaline-earth cations is well known. ${ }^{1}$ Many research works have been done recently to find the most efficient way to immobilize 8-hydroxyquinoline on a number of different substrates, including glass beads, ${ }^{2,3}$ silica $^{4-6}$ and vinyl polymers. ${ }^{7}$ Trace element determination methods have also involved precomplexation of analytes with a solution of the ligand and then concentration on Amberlite. ${ }^{8}$

Among these supports, silica gel is the most often used material. ${ }^{9}, 10$ It offers good mechanical strength, resistance to swelling and rapid overall exchange kinetics in column applications. ${ }^{11}$ However, silica gel is unstable at high $\mathrm{pH}$, leading to cleavage of the immobilized 8-hydroxyquinoline and potential trace metal contamination from the newly exposed silica surface. ${ }^{12,13}$

The preparation and properties of condensation resins of the resorcinol-formaldehyde-8-hydroxyquinoline type have also been investigated.14,15 Although these resins offer higher exchange capacities, their obvious drawbacks are low stability in acid solution and slower overall kinetic exchange rates.

The immobilization of 8-hydroxyquinoline onto polystyrene-divinylbenzene resins is apparently quite stable with respect to extremes of $\mathrm{pH}$ and can be produced with high total exchange capacity. But the overall kinetic exchange rate is also reported to be slow. ${ }^{14,15}$

In the previous work of our group, poly(acrylammophosphonicdithiocarbamate) chelating fiber was successfully used to preconcentrate REEs from seawater, but synthesis of this fiber is a time consuming four-step procedure ${ }^{16}$. The aim of this study is to synthesize 8-hydroxyquinoline immobilized onto polyacrylonitrile (PAN) hollow fiber membrane for the preconcentration of REEs and the separation of the matrix in seawater prior to the determination of the REEs by ICP-MS.

\section{Experimental}

\section{Instruments}

A Plasma-Quad 3 (VG Elemental, Winsford, UK) inductively coupled plasma mass spectrometer (ICP-MS) was used for the determination of the REEs. The optimum instrumental parameters are given in Table 1. Calcium, magnesium, sodium and potassium were determined by inductively coupled plasma atomic emission spectroscopy (ICP-AES) (Jarrell-Ash Model 1155, AtomComp, USA). The operating conditions for the determinations were optimized. Corrections for background shift and spectral interferences were performed. 


\section{Reagent and solutions}

Stock solutions of each REE, $1000 \mu \mathrm{g} \mathrm{ml}{ }^{-1}$, were prepared by dissolving the appropriate amount of metal oxide (Specpure, Johnson Matthey Chemicals Limited, UK) in $5 \mathrm{ml}$ of nitric acid $(67 \%)$. If complete dissolution was not achieved, $1 \mathrm{ml} \mathrm{HCl}$ $(37 \%)$ was added and moderate heating was applied. Single and multi-element standard solutions with concentrations of 10, 50 and $100 \mathrm{ng} \mathrm{ml}^{-1}$ were prepared from the stock solutions before use by dilution with dilute $\mathrm{HNO}_{3}$. The final acid concentration of all the standard solutions was fixed at $0.1 \mathrm{~mol} \mathrm{l}^{-1} \mathrm{HNO}_{3}$.

All other reagents were of analytical grade or better. High purity water $(18 \mathrm{M} \Omega \mathrm{cm})$ was prepared by double distillation of deionized water in a fused quartz still (Westdeutsche Quarzschmelze, Geesthacht, Germany). Nitric acid was purified by subboiling distillation in a quartz still using ultrapure grade $\mathrm{HNO}_{3}$ as feed. All other acids used were of ultrapure grade (Beijing Chemicals, China). Indium was added as an internal standard to monitor matrix effects and signal drift.

Polyacrylonitrile hollow fiber membrane was obtained from Zhong Ke Membrane Research \& Development Center, Beijing, China, and was rinsed with nitric acid $(1+1)$, hydrochloric acid $(1+1)$ and doubly distilled deionized water sequentially before use.

Prior to use, all beakers, funnels, calibrated flasks and other glassware were cleaned sequentially with tap water, neutral detergent, tap water, then soaked in nitric acid $(1+1)$ for $48 \mathrm{~h}$ and cleaned with doubly deionized distilled water before use.

\section{Immobilization procedure}

The hydrazine-modified PAN fiber was synthesized following the method of Zhang et al. ${ }^{17}$ Twenty grams of rinsed PAN hollow fiber membrane and $800 \mathrm{ml}$ of hydrazine hydrate (26.7\%) were brought together in a 11 flat-flange reaction vessel and reacted for $2.5 \mathrm{~h}$ at $90-94^{\circ} \mathrm{C}$. The hydrazine-modified PAN hollow fiber membrane was filtered and washed with doubly distilled deionized water until the $\mathrm{pH}$ was neutral and then washed again with $300 \mathrm{ml}$ of ethanol (99.5\%).

Table 1 ICP-MS operating conditions

\begin{tabular}{|c|c|}
\hline \multicolumn{2}{|l|}{ ICP system- } \\
\hline Forward power & $1350 \mathrm{~W}$ \\
\hline Reflected power & $<5 \mathrm{~W}$ \\
\hline Coolant argon flow rate & $141 \min ^{-1}$ \\
\hline Auxiliary gas flow rate & $0.911 \mathrm{~min}^{-1}$ \\
\hline Nebulizer gas flow rate & 0.81 \\
\hline Sample uptake rate & $1.0 \mathrm{ml} \mathrm{min}-1$ \\
\hline Sampling depth & $15 \mathrm{~mm}$ \\
\hline \multicolumn{2}{|l|}{ Mass spectrometer- } \\
\hline Sampler (nickel) orifice & $1.0 \mathrm{~mm}$ \\
\hline Skimmer (nickel) orifice & $0.7 \mathrm{~mm}$ \\
\hline 3rd stage pressure & $1.7 \times 10^{-1} \mathrm{mPa}$ \\
\hline Data acquisition & Range scanning mode \\
\hline Total acquisition time & $60 \mathrm{~s}$ \\
\hline Element & Mass \\
\hline $\mathrm{Y}$ & 89 \\
\hline $\mathrm{La}$ & 139 \\
\hline $\mathrm{Ce}$ & 140 \\
\hline $\operatorname{Pr}$ & 141 \\
\hline $\mathrm{Nd}$ & 146 \\
\hline $\mathrm{Sm}$ & 147 \\
\hline $\mathrm{Eu}$ & 151 \\
\hline $\mathrm{Gd}$ & 157 \\
\hline $\mathrm{Tb}$ & 159 \\
\hline Dy & 162 \\
\hline Ho & 165 \\
\hline $\mathrm{Er}$ & 166 \\
\hline $\mathrm{Tm}$ & 169 \\
\hline $\mathrm{Yb}$ & 174 \\
\hline $\mathrm{Lu}$ & 175 \\
\hline
\end{tabular}

The hydrazine-modified PAN hollow fiber membrane was soaked in a $400 \mathrm{ml}$ solution of $20 \mathrm{~g}$ of $\mathrm{NaNO}_{2}$ in $0.2 \mathrm{~mol} \mathrm{l}^{-1}$ acetic acid for $1 \mathrm{~h}$ at $0{ }^{\circ} \mathrm{C}$. The product was filtered and rinsed with ice-cold doubly distilled deionized water and then added to a $50 \mathrm{ml}$ solution of $1 \mathrm{~g}$ of 8-hydroxyquinoline in $95 \% \mathrm{EtOH}$. After $1 \mathrm{~h}$ reaction, the pink diazo-coupled 8-hydroxyquinoline product was filtered and rinsed sequentially with $500 \mathrm{ml} 0.5 \mathrm{~mol}$ $1^{-1} \mathrm{NaOH}, 500 \mathrm{ml} \mathrm{H}_{2} \mathrm{O}, 500 \mathrm{ml} 1.0 \mathrm{~mol} \mathrm{1}^{-1} \mathrm{HCl}$, and three portions of $500 \mathrm{ml}$ doubly deionized distilled water. The hollow fiber membrane was then soaked in deionized distilled water before use.

\section{Fiber capacity}

The chelating capacity of this 8-hydroxyquinoline immobilized PAN hollow fiber membrane was determined for each REE by a batch technique. Membrane ( $\approx 100 \mathrm{mg}$ ) was equilibrated with each REE by shaking for $24 \mathrm{~h}$ at $\mathrm{pH} 6$ in an excess of metal ion solution $\left(10 \mathrm{ml}, 50 \mu \mathrm{g} \mathrm{ml}^{-1}\right)$. The membrane was then separated from the solution by filtration and the concentration of the metal ion remaining in the solution was determined by ICP-MS.

\section{Sampling of seawater}

The polyethylene bottles (10 1) used for sampling the seawater were precleaned with detergent, doubly deionized distilled water, dilute $\mathrm{HNO}_{3}$ and doubly deionized distilled water successively, and $10 \mathrm{ml}$ of high-purity $\mathrm{HNO}_{3}$ was added to keep the final acidity of the seawater at about $\mathrm{pH} 2$ after sampling. Seawater samples were taken at a depth of $1 \mathrm{~m}$ from four locations in October, 1997. The sample localities are situated at a distance of approximately 10 miles from the cities of Tianjin, Qinghuangdao, Dalian and Qingdao along the eastern and northern coasts of China. The samples were filtered through a Millipore cellulose membrane with a pore size of $0.45 \mu \mathrm{m}$ and stored at a temperature of $4{ }^{\circ} \mathrm{C}$.

\section{Package of 8-hydroxyquinoline immobilized PAN hollow fiber membrane column}

Eight batches of 8-hydroxyquinoline modified PAN hollow fiber membrane (length $60 \mathrm{~mm}$, id $0.5 \mathrm{~mm}$, weight about $0.3 \mathrm{~g}$ ) were inserted into a T-glass column (length $60 \mathrm{~mm}$, id $6 \mathrm{~mm}$ ). The column was drained and rinsed several times with $\mathrm{HNO}_{3}$ $(1+1)$ and doubly deionized distilled water sequentially prior to use. At each end of the glass column, 8-hydroxyquinoline immobilized PAN hollow fiber membrane was fixed with epoxy resin. One end of the glass column was sealed with a Teflon stopcock. The column assembly is shown in Fig. 1.

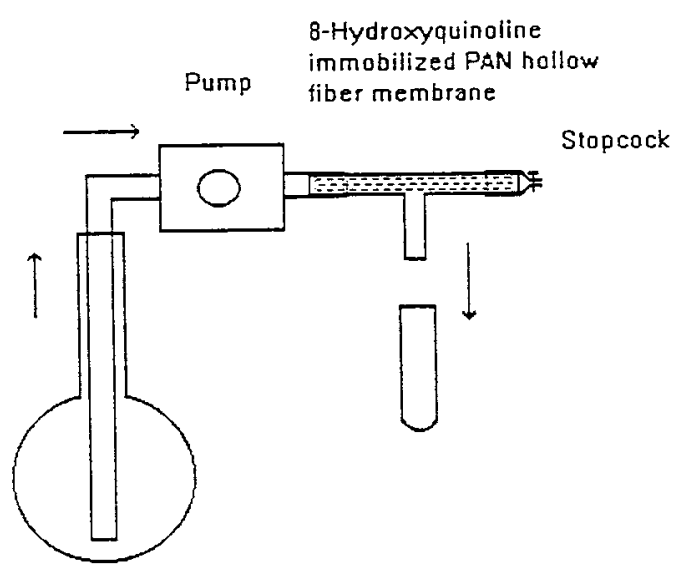

Fig. 1 Scheme of the preconcentration apparatus. 
Prior to use, the entire assembly was carefully rinsed first with sufficient distilled water, then with $100 \mathrm{ml}$ of $1 \mathrm{~mol}^{-1}$ $\mathrm{HCl}-0.1 \mathrm{~mol} \mathrm{l}^{-1} \mathrm{HNO}_{3}$, finally with doubly deionized distilled water again until the $\mathrm{pH}$ of the eluate was neutral.

\section{Preconcentration of REEs from seawater}

A $1500 \mathrm{ml}$ seawater sample was adjusted to the desired $\mathrm{pH} 6$ using high purity ammonium hydroxide and nitric acid, then introduced into the immobilized PAN hollow fiber membrane using a peristaltic pump at the flow rate of $10 \mathrm{ml} \mathrm{min}^{-1}$. After washing with $50 \mathrm{ml}$ doubly deionized distilled water, the REEs retained in the column were eluted with $5 \mathrm{ml}$ of $1 \mathrm{~mol} \mathrm{l}^{-1} \mathrm{HCl}-$ $0.1 \mathrm{~mol} \mathrm{l}^{-1} \mathrm{HNO}_{3}$ at a flow rate of $1 \mathrm{ml} \mathrm{min}-1$.

\section{Results and discussion}

\section{Characterization and properties of 8-hydroxyquinoline modified PAN hollow fiber membrane}

(1) The capacity of modified PAN hollow fiber membrane. The binding capacity is an important factor in determining how much fiber membrane is required to quantitatively concentrate the analytes of interest from seawater. In order to compare the capacity of the PAN hollow fiber membrane with other researcher's yields, the capacity of $\mathrm{Cu}(\mathrm{II})$ was also studied; $\mathrm{Cu}$ (II) has been used as an indicating species in the literature. Following the procedure described in the Experimental section, the capacity of $\mathrm{Cu}, \mathrm{Y}, \mathrm{La}, \mathrm{Ce}, \mathrm{Pr}, \mathrm{Nd}, \mathrm{Sm}, \mathrm{Eu}$, $\mathrm{Gd}, \mathrm{Tb}, \mathrm{Dy}, \mathrm{Ho}, \mathrm{Er}, \mathrm{Tm}, \mathrm{Yb}$ and $\mathrm{Lu}$ were found to be 71.55 , $22.66,22.13,22.91,23.13,25.66,27.12,23.46,25.94,25.17$, 27.46, 26.74, 24.84, 27.66, 21.83 and $29.08 \mu \mathrm{mol} \mathrm{g}^{-1}$, respectively, under the optimum $\mathrm{pH} 6$, which will be discussed later. Compared with the chelating capacity of $\mathrm{Cu}(\mathrm{II})$ reported for silica-immobilized 8-hydroxyquinoline, this value is lower than Marshall and Mottola's yield ${ }^{18}$ of $185 \mu \mathrm{mol} \mathrm{g}^{-1} \mathrm{Cu}$ (II), but it is greater than Sturgeon et al.' $\mathrm{s}^{19}$ value of $61 \mu \mathrm{mol} \mathrm{g}{ }^{-1} \mathrm{Cu}$ (II) and Daih and Huang's product ${ }^{4}$ of $10.4 \mu \mathrm{mol} \mathrm{g}^{-1} \mathrm{Cu}(\mathrm{II})$. In light of the extremely low levels of REEs in seawater, the exchange capacity of the modified PAN hollow fiber membrane is sufficient for the preconcentration of REEs from seawater.

(2) The stability of the modified PAN hollow fiber membrane. Batch capacity studies were chosen for the determination of the chemical stability of the modified PAN hollow fiber membrane. Copper(II) was also used as an indicating species. After 2 and $48 \mathrm{~h}$ of acid treatment $\left(1 \mathrm{~mol} \mathrm{l}^{-1}\right.$ $\mathrm{HCl}-0.1 \mathrm{~mol} \mathrm{l}^{-1} \mathrm{HNO}_{3}$ ), the batch capacity for $\mathrm{Cu}(\mathrm{II})$ was found to be 71.53 and $71.23 \mu \mathrm{mol} \mathrm{g}^{-1}$ respectively. This indicated that the modified PAN hollow fiber membrane was quite stable in acid solution.

If the 8-hydroxyquinoline immobilized PAN hollow fiber membrane was treated with $0.5 \mathrm{~mol} 1^{-1} \mathrm{NaOH}$ for $2 \mathrm{~h}$, the batch capacity remained at the same level $\left(71.43 \mu \mathrm{mol} \mathrm{Cu}(\mathrm{II}) \mathrm{g}^{-1}\right)$. It also should be pointed out that after $48 \mathrm{~h}$ of exposure, the color of the 8-hydroxyquinoline immobilized PAN hollow fiber membrane was changed to yellowish orange. However, the batch capacity increased to $101.62 \mu \mathrm{mol} \mathrm{Cu}$ (II) $\mathrm{g}^{-1}$. This may be due to the hydrolysis of nitrile groups, leading to the formation of carboxy groups. ${ }^{17}$

\section{Optimum conditions for the preconcentration of REEs} and separation of matrix in seawater

To obtain quantitative recoveries of the metal ions on the 8-hydroxyquinoline immobilized PAN hollow fiber membrane, the experimental parameters were optimized, including $\mathrm{pH}$, sample volume and flow rate, and matrix separation. The concentration of each REE in the model solution for this purpose ranged from 5 to $10 \mu \mathrm{g}^{-1}$.

(1) Effect of $\mathrm{pH}$ on the preconcentration efficiency. The effect of $\mathrm{pH}$ on the preconcentration efficiency was studied from 1 to 9. The results are graphically shown in Fig. 2. It can be seen that all the REEs were adsorbed quantitatively ( $>95 \%$ ) over a wide $\mathrm{pH}$ range of 3-9. Hence, a $\mathrm{pH}$ of 6 was fixed as the optimum acidity condition for simultaneous REE preconcentration.

(2) Effect of eluent volume. An eluent of $1 \mathrm{~mol} \mathrm{l}^{-1} \mathrm{HCl}-0.1$ mol $1^{-1} \mathrm{HNO}_{3}$ has been used by many researchers to elute analytes chelated with 8-hydroxyquinoline immobilized silica gel..$^{4,18}$ In this study, various volumes of $1 \mathrm{~mol} \mathrm{l}^{-1} \mathrm{HCl}-0.1$ mol $1^{-1} \mathrm{HNO}_{3}$ were used to elute the adsorbed metal ions after the REEs were concentrated from $1500 \mathrm{ml}$ of sample solution at a level of $5 \mu \mathrm{g} 1^{-1}$ (Fig. 3). It can be seen that when the volume of eluent was less than $4 \mathrm{ml}$, no quantitative recoveries ( > 95\%)

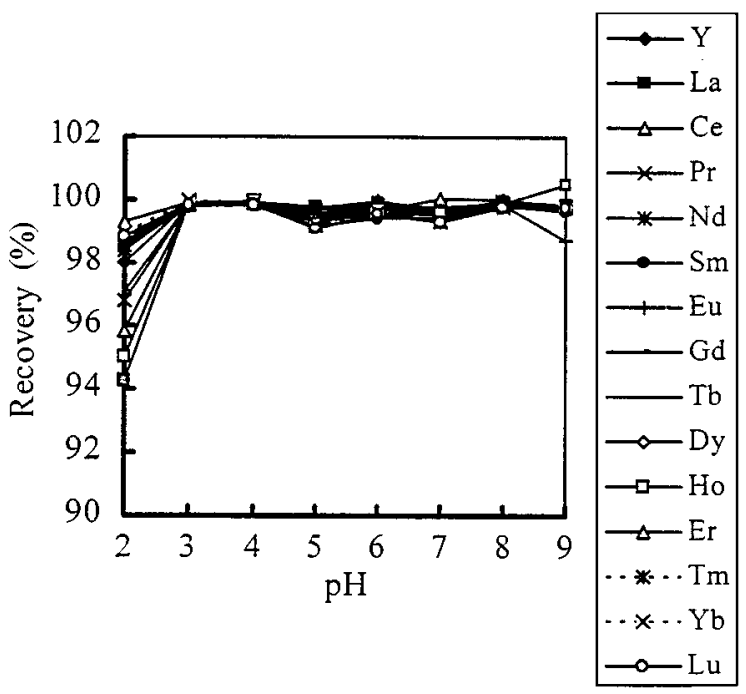

Fig. 2 Effect of sample $\mathrm{pH}$ on concentration efficiency of REEs (sample

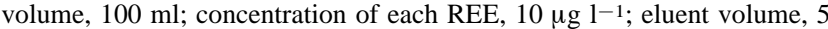
$\mathrm{ml})$.

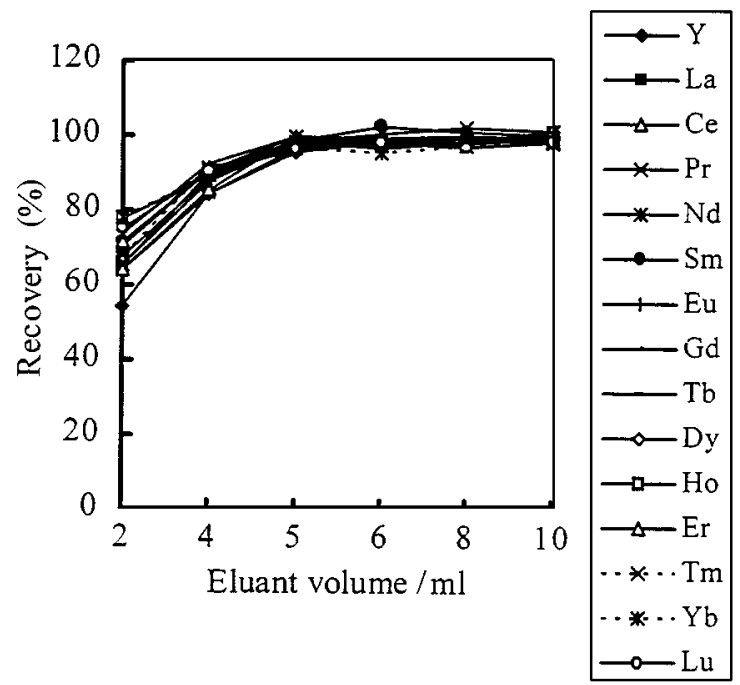

Fig. 3 Elution efficiency of REEs as a function of the eluent volume (sample volume, $1.5 \mathrm{l}$; concentration of each REE, $5 \mu \mathrm{g}^{-1}$; eluent, 1 mol 1-1 $\left.\mathrm{HCl}-0.1 \mathrm{~mol} \mathrm{l}^{-1} \mathrm{HNO}_{3}\right)$. 
could be obtained. However, quantitative recoveries were obtained over the eluent volume range from 5 to $10 \mathrm{ml}$. In order to achieve a higher concentration factor, $5 \mathrm{ml}$ of eluent was used in the remainder of the study.

(3) Effect of flow rate and volume of sample. Owing to the large volume of sample needed, it was desirable to pump it at the maximum flow rate achievable without sacrifice of the recoveries. The effect of different flow rates of sample solution through the 8-hydroxyquinoline immobilized PAN hollow fiber membrane on the concentration efficiency was tested at flow rates from 1 to $10 \mathrm{ml} \mathrm{min}^{-1}$ at $\mathrm{pH} 6$ (Fig. 4). It can be seen that the recoveries of all REEs were quantitative at flow rates of $1-10 \mathrm{ml} \mathrm{min}-1$ and a flow rate of $10 \mathrm{ml} \mathrm{min}^{-1}$ was used in the following study.

In order to explore the possibility of enriching the low concentration of REEs with a high preconcentration factor, the effect of sample volume on the concentration efficiency was also studied and the results are given in Fig. 5. Quantitative recoveries ( $>95 \%$ ) were obtained when the sample volume was less than $1500 \mathrm{ml}$. When the sample volume exceeds this volume limitation, the recoveries for all the REEs decreased. The same phenomenon was also found in some other works. ${ }^{20,21}$ The reason why the recoveries decreased with

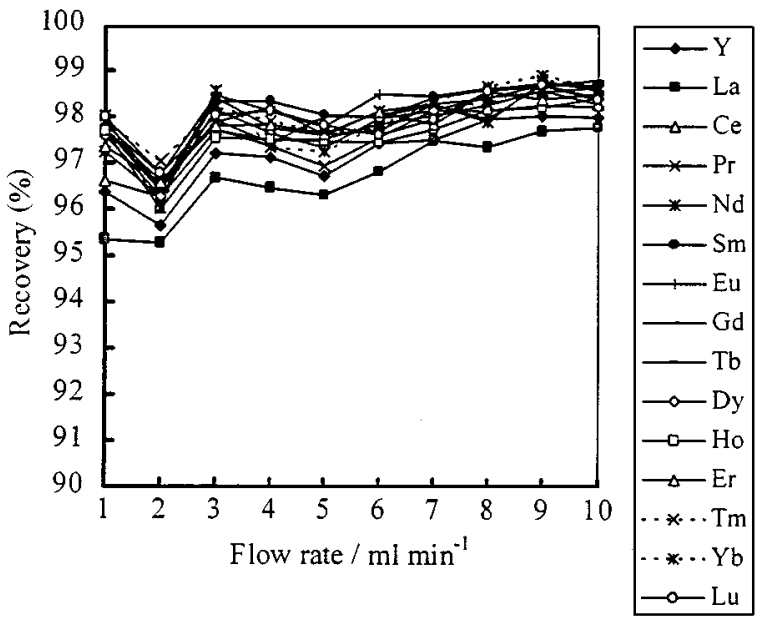

Fig. 4 Effect of the sample flow rate on the concentration efficiency of REEs (sample volume, $1.5 \mathrm{l}$; concentration of each REE, $10 \mu \mathrm{g}^{-1}$; eluent volume, $5 \mathrm{ml} ; n=5$ ). increasing sample volume may be that some ions present in the sample might act as eluents, if their affinity for the fiber is sufficiently large. Therefore, when the sample volume increases, early breakthrough is possible. ${ }^{22}$ In this experiment, 1.5 1 of sample solution was adopted for the preconcentration of REEs in seawater, and the adsorbed REEs were eluted with $5 \mathrm{ml}$ of $1 \mathrm{moll}^{-1} \mathrm{HCl}-0.1 \mathrm{~mol} \mathrm{l}^{-1} \mathrm{HNO}_{3}$; the preconcentration factor was found to be 300 -fold.

(4) Separation of matrix. The separation of the major matrix components in seawater, such as sodium, potassium, calcium and magnesium, was investigated in order to elucidate the effectiveness of the matrix separation. It has been already mentioned in the introduction that the high salt content of seawater prohibits the direct determination of trace elements by ICP-MS; effective separation of the matrix components is another requisite in addition to the preconcentration of the analytes of interest. Therefore, experimental work was conducted to verify if the 8-hydroxyquinoline immobilized PAN hollow fiber membrane could separate the matrix components of seawater without any sacrifice of the concentration efficiency for REEs. Synthetic solutions $(1500 \mathrm{ml})$ in which the concentration of each REE was fixed at $5 \mu \mathrm{g} 1^{-1}$ and the matrix concentration for $\mathrm{Na}^{+}, \mathrm{K}^{+}, \mathrm{Mg}^{2+}$ and $\mathrm{Ca}^{2+}$ (as chlorides) was $20000,500,2500$ and $500 \mathrm{mg}^{-1}$, respectively, were passed

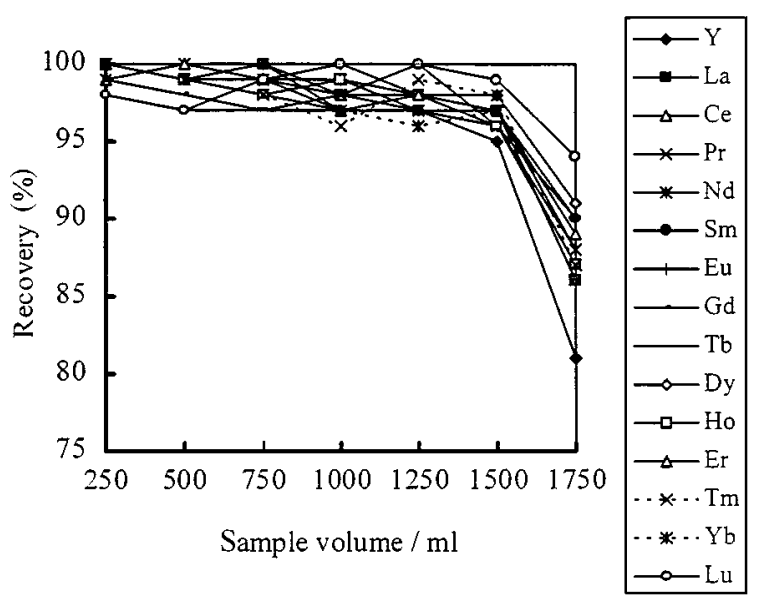

Fig. 5 Effect of the sample volume on the concentration efficiency of REEs (concentration of each REE, $5 \mu \mathrm{g} 1^{-1}$; eluent volume, $5 \mathrm{ml} ; n=$ 5).

Table 2 Influence of matrix ions on the concentration efficiency for REEs (sample volume, $1500 \mathrm{ml}$; concentration of each REE, $5 \mu \mathrm{g}{ }^{-1}$; eluent volume, $5 \mathrm{ml} ; n=3$ )

\begin{tabular}{|c|c|c|c|c|}
\hline & \multicolumn{4}{|c|}{ Matrix ion (added as) } \\
\hline & $\mathrm{Na}^{+}(\mathrm{NaCl})$ & $\mathrm{K}^{+}(\mathrm{KCl})$ & $\mathrm{Mg}^{2+}\left(\mathrm{MgCl}_{2}\right)$ & $\mathrm{Ca}^{2+}\left(\mathrm{CaCl}_{2}\right)$ \\
\hline Concentration of matrix ions in the sample/mg $1^{-1}$ & 20000 & 500 & 2500 & 500 \\
\hline Concentration of matrix ions in the eluent/mg $1^{-1}$ & 2.6 & 0.85 & 4.86 & 2.8 \\
\hline \multicolumn{5}{|l|}{ Recovery (\%) } \\
\hline $\mathrm{La}$ & 100 & 99 & 100 & 100 \\
\hline $\mathrm{Ce}$ & 100 & 101 & 99 & 97 \\
\hline $\operatorname{Pr}$ & 99 & 100 & 99 & 97 \\
\hline $\mathrm{Nd}$ & 100 & 101 & 98 & 98 \\
\hline $\mathrm{Sm}$ & 100 & 100 & 102 & 100 \\
\hline $\mathrm{Eu}$ & 98 & 98 & 98 & 99 \\
\hline $\mathrm{Gd}$ & 99 & 99 & 97 & 97 \\
\hline $\mathrm{Tb}$ & 105 & 103 & 102 & 100 \\
\hline $\mathrm{Er}$ & 100 & 100 & 98 & 100 \\
\hline Ho & 100 & 100 & 99 & 96 \\
\hline Dy & 98 & 99 & 97 & 100 \\
\hline $\mathrm{Em}$ & 100 & 100 & 98 & 98 \\
\hline $\mathrm{Yb}$ & 99 & 100 & 100 & 98 \\
\hline $\mathrm{Lu}$ & 99 & 99 & 98 & 100 \\
\hline $\mathrm{Y}$ & 96 & 100 & 102 & 102 \\
\hline
\end{tabular}


through the column. The REEs retained on the column were eluted with $5 \mathrm{ml}$ of $1 \mathrm{~mol} \mathrm{1}^{-1} \mathrm{HCl}-0.1 \mathrm{~mol}^{-1} \mathrm{HNO}_{3}$. The concentration of the REEs and the matrix components in the eluent was determined by ICP-MS and ICP-AES, respectively. The results are shown in Table 2 . It was verified that the salt contents in the eluent were significantly lower, which is suitable for ICP-MS determination, and that the recoveries of the REEs were satisfactory. Therefore, no additional separation procedure was needed. This indicates that 8-hydroxyquinoline immobilized PAN hollow fiber membrane can be used to concentrate ultratrace REEs from high saline seawater for determination by ICP-MS.

(5) Blank and detection limits. The detection limits and the blank values are shown in Table 3. The blank value for REE determination was obtained by performing the preconcentration procedure using $1500 \mathrm{ml}$ of doubly deionized distilled water as a sample and $5 \mathrm{ml}$ of $1 \mathrm{~mol} \mathrm{1}^{-1} \mathrm{HCl}-0.1 \mathrm{~mol} \mathrm{l}^{-1} \mathrm{HNO}_{3}$ as eluent. The detection limits of the method were calculated based on three times the standard deviation of 11 runs of the blank solution. Compared with the concentration of REEs present in seawater samples (Table 4), all the REE concentrations in the real samples are much greater than the detection limits after 300 -fold preconcentration.
Table 3 Blanks and detection limits

\begin{tabular}{lll}
\hline Element & Blank/ng $1^{-1}$ & $\begin{array}{l}\text { Detection } \\
\text { limit/ng } 1^{-1}\end{array}$ \\
\hline $\mathrm{Y}$ & 3.9 & 2.1 \\
$\mathrm{La}$ & 4.0 & 2.7 \\
$\mathrm{Ce}$ & 2.8 & 1.6 \\
$\mathrm{Pr}$ & 2.0 & 0.91 \\
$\mathrm{Nd}$ & 1.9 & 1.7 \\
$\mathrm{Sm}$ & 3.0 & 1.8 \\
$\mathrm{Eu}$ & 1.8 & 0.71 \\
$\mathrm{Gd}$ & 2.0 & 1.1 \\
$\mathrm{~Tb}$ & 0.9 & 0.56 \\
$\mathrm{Dy}$ & 1.0 & 0.73 \\
$\mathrm{Ho}$ & 1.0 & 0.24 \\
$\mathrm{Er}$ & 0.6 & 0.21 \\
$\mathrm{Tm}$ & 0.8 & 0.53 \\
$\mathrm{Yb}$ & 0.7 & 0.31 \\
$\mathrm{Lu}$ & 0.6 & 0.32 \\
\hline
\end{tabular}

\section{Determination of trace metal in seawater}

Because no certified reference values were available for REEs in seawater, trace REEs equal to the same level of the REEs present in seawater were spiked before matrix separation and

Table 4 Determination of REEs in seawater (ng $\left.1^{-1}\right)$ and spiked recovery (\%) (sample volume, 1.5 1; eluent volume, $\left.5 \mathrm{ml}\right)^{a}$

\begin{tabular}{|c|c|c|c|c|c|c|c|c|c|c|c|c|c|c|c|c|}
\hline \multirow[b]{2}{*}{ Element } & \multicolumn{4}{|c|}{ Tianjin seawater } & \multicolumn{4}{|c|}{ Dalian seawater } & \multicolumn{4}{|c|}{ Qingdao seawater } & \multicolumn{4}{|c|}{ Qinghuangdao seawater } \\
\hline & Found & Added & $\begin{array}{l}\text { Total } \\
\text { found }\end{array}$ & $\begin{array}{l}\mathrm{Re}- \\
\text { covery }\end{array}$ & Found & Added & $\begin{array}{l}\text { Total } \\
\text { found }\end{array}$ & $\begin{array}{l}\text { Re- } \\
\text { covery }\end{array}$ & Found & Added & $\begin{array}{l}\text { Total } \\
\text { found }\end{array}$ & $\begin{array}{l}\text { Re- } \\
\text { covery }\end{array}$ & Found & Added & $\begin{array}{l}\text { Total } \\
\text { found }\end{array}$ & $\begin{array}{l}\mathrm{Re}- \\
\text { covery }\end{array}$ \\
\hline $\mathrm{Y}$ & 13.3 & 13.0 & 26.4 & 101 & 13.6 & 13.5 & 26.9 & 99 & 12.8 & 13.0 & 26.0 & 102 & 11.8 & 12.0 & 23.5 & 98 \\
\hline $\mathrm{La}$ & 3.84 & 3.80 & 7.56 & 98 & 3.14 & 3.10 & 6.33 & 103 & 3.27 & 3.50 & 6.90 & 104 & 3.50 & 3.50 & 7.01 & 100 \\
\hline $\mathrm{Ce}$ & 7.30 & 7.30 & 14.5 & 99 & 6.73 & 6.70 & 13.0 & 94 & 6.35 & 6.30 & 12.7 & 101 & 7.30 & 7.30 & 15.1 & 107 \\
\hline $\operatorname{Pr}$ & 1.20 & 1.20 & 2.38 & 98 & 1.86 & 1.90 & 3.65 & 94 & 1.08 & 1.10 & 2.23 & 104 & 1.75 & 1.80 & 3.49 & 97 \\
\hline $\mathrm{Nd}$ & 2.85 & 2.80 & 5.48 & 94 & 3.20 & 3.20 & 6.25 & 95 & 3.66 & 3.70 & 7.52 & 104 & 3.21 & 3.20 & 6.35 & 98 \\
\hline $\mathrm{Sm}$ & 1.05 & 1.00 & 2.10 & 105 & 1.15 & 1.20 & 2.38 & 102 & 1.36 & 1.40 & 2.80 & 103 & 1.30 & 1.30 & 2.55 & 96 \\
\hline $\mathrm{Eu}$ & 0.423 & 0.420 & 0.841 & 100 & 0.456 & 0.450 & 0.900 & 99 & 0.372 & 0.350 & 0.700 & 94 & 0.423 & 0.42 & 0.834 & 98 \\
\hline $\mathrm{Gd}$ & 1.20 & 1.20 & 2.29 & 91 & 1.49 & 1.50 & 2.97 & 99 & 1.26 & 1.30 & 2.55 & 99 & 1.33 & 1.30 & 2.65 & 102 \\
\hline $\mathrm{Tb}$ & 0.345 & 0.35 & 0.676 & 94 & 0.297 & 0.300 & 0.589 & 97 & 0.251 & 0.250 & 0.500 & 100 & 0.375 & 0.380 & 0.764 & 102 \\
\hline Dy & 0.869 & 0.870 & 1.67 & 92 & 1.06 & 1.10 & 2.13 & 97 & 0.961 & 0.960 & 1.99 & 107 & 1.05 & 1.10 & 2.09 & 94 \\
\hline Ho & 0.355 & 0.360 & 0.719 & 101 & 0.25 & 0.25 & 0.481 & 92 & 0.230 & 0.230 & 0.469 & 104 & 0.300 & 0.300 & 0.589 & 96 \\
\hline $\mathrm{Er}$ & 1.09 & 1.10 & 2.21 & 102 & 1.04 & 1.00 & 2.04 & 100 & 0.944 & 0.900 & 1.899 & 106 & 1.07 & 1.10 & 1.97 & 97 \\
\hline $\mathrm{Tm}$ & 0.211 & 0.210 & 0.420 & 100 & 0.245 & 0.250 & 0.500 & 102 & 0.240 & 0.240 & 0.469 & 95 & 0.207 & 0.210 & 0.410 & 97 \\
\hline $\mathrm{Yb}$ & 1.15 & 1.10 & 2.31 & 105 & 0.935 & 0.900 & 1.900 & 107 & 0.978 & 1.00 & 1.99 & 101 & 0.998 & 1.00 & 1.97 & 97 \\
\hline $\mathrm{Lu}$ & 0.201 & 0.200 & 0.400 & 100 & 0.156 & 0.160 & 0.325 & 106 & 0.199 & 0.200 & 0.401 & 101 & 0.210 & 0.200 & 0.400 & 95 \\
\hline
\end{tabular}

Table 5 Comparison of REE concentration in seawater $\left(n g 1^{-1}\right)$ obtained by this method with the reported values

\begin{tabular}{|c|c|c|c|c|c|c|c|c|c|c|c|}
\hline \multirow[b]{3}{*}{ Element } & \multirow{2}{*}{\multicolumn{4}{|c|}{ Present method }} & \multicolumn{7}{|c|}{ Literature values } \\
\hline & & & & & \multicolumn{4}{|l|}{ Ref. 16} & \multirow[b]{2}{*}{ Ref. 23} & \multirow[b]{2}{*}{ Ref. 21} & \multirow[b]{2}{*}{ Ref. 24} \\
\hline & Tianjin & Dalian & Qingdao & Qinghuangdao & Tianjin & Dalian & Qingdao & Qinghuangdao & & & \\
\hline $\mathrm{Y}$ & 13.3 & 13.6 & 12.8 & 11.8 & 13.8 & 13.6 & 12.9 & 11.8 & & & \\
\hline $\mathrm{La}$ & 3.84 & 3.14 & 3.27 & 3.50 & 3.74 & 3.34 & 3.57 & 3.50 & 3.8 & 3.49 & \\
\hline $\mathrm{Ce}$ & 7.30 & 6.73 & 6.35 & 7.30 & 7.16 & 6.82 & 6.32 & 7.30 & 6.1 & 5.03 & 6.53 \\
\hline $\operatorname{Pr}$ & 1.20 & 1.86 & 1.08 & 1.75 & 1.12 & 1.86 & 1.06 & 1.71 & 0.7 & 0.731 & 2.61 \\
\hline $\mathrm{Nd}$ & 2.85 & 3.20 & 3.66 & 3.21 & 2.82 & 3.17 & 3.66 & 3.01 & 2.7 & 3.26 & 6.05 \\
\hline $\mathrm{Sm}$ & 1.05 & 1.15 & 1.36 & 1.30 & 1.05 & 1.23 & 1.36 & 1.29 & 0.5 & 0.607 & 2.62 \\
\hline $\mathrm{Eu}$ & 0.423 & 0.456 & 0.372 & 0.423 & 0.411 & 0.448 & 0.352 & 0.423 & 0.2 & 0.180 & 2.09 \\
\hline $\mathrm{Gd}$ & 1.20 & 1.49 & 1.26 & 1.33 & 1.19 & 1.45 & 1.26 & 1.32 & 0.7 & 0.985 & 1.28 \\
\hline $\mathrm{Tb}$ & 0.345 & 0.297 & 0.251 & 0.375 & 0.332 & 0.286 & 0.248 & 0.387 & 0.2 & 0.17 & 0.31 \\
\hline Dy & 0.869 & 1.06 & 0.961 & 1.05 & 0.851 & 1.06 & 0.954 & 1.09 & 0.9 & 0.976 & 1.67 \\
\hline Ho & 0.355 & 0.250 & 0.230 & 0.300 & 0.354 & 0.250 & 0.230 & 0.305 & 0.3 & 0.25 & 0.31 \\
\hline Er & 1.09 & 1.04 & 0.944 & 1.07 & 1.06 & 1.04 & 0.955 & 1.07 & 0.7 & 0.730 & 1.02 \\
\hline $\mathrm{Yb}$ & 1.15 & 0.935 & 0.978 & 0.998 & 1.13 & 0.925 & 0.938 & 0.994 & 0.8 & 0.634 & 0.31 \\
\hline $\mathrm{Lu}$ & 0. 201 & 0.156 & 0.199 & 0.210 & 0.198 & 0.151 & 0.194 & 0.209 & 0.2 & 0.102 & \\
\hline
\end{tabular}


preconcentration. The determination of REEs in seawater and recoveries of the spikes are given in Table 4; together these show the high reliability, validity and sufficiently high recoveries (91-107\%) of the method. A comparison was also made (Table 5) between the data obtained by the proposed method and those reported in the literature, 16,21,23,24 and a reasonably good agreement was also achieved.

\section{Conclusion}

In this study, a new successful technique has been developed based on an 8-hydroxyquinoline immobilized PAN hollow fiber membrane for preconcentration of REEs and separation of the matrix components in seawater prior to determination by ICPMS. All REEs can be easily concentrated 300 times with almost all the matrix elements separated. This method has the following advantages over previously reported ones: (1) the preparation time of the immobilized PAN hollow fiber membrane is relatively short compared with the preparation time reported in the literature for 8-hydroxyquinoline immobilized on other substrates; (2) only a single-stage process is required for the preconcentration of the REEs and the separation of the matrix components from seawater; the salinity in the eluent is considerably reduced, so that the final eluent can be run by ICP-MS; (3) all REEs can be preconcentrated over a wide $\mathrm{pH}$ range, therefore no buffer is required to control the $\mathrm{pH}$, which thereby minimizes the contamination; (4) in this paper, although only the REEs were preconcentrated, one can expect that other trace elements can be preconcentrated.

\section{Acknowledgement}

The study was supported by the National Natural Science Foundation of China.

\section{References}

1 R. A. Nickson, S. J. Hill and P. J. Worsfold, Anal. Proc., 1995, 32, 387.

2 D. E. Leyden, G. H. Luttrell, A. E. Sloan and N. J. DeAngells, Anal. Chim. Acta, 1976, 84, 97.

3 J. A. Buono, R. W. Karin and J. L. Fasching, Anal. Chim. Acta, 1975, 80, 327.

4 B. Daih and H. Huang, Anal. Chim. Acta, 1992, 258, 245.

5 B. K. Esser, A. Volpe, J. M. Kenneally and K. K. Smith, Anal. Chem., 1994, 66, 1736.

6 J. W. McLaren, K. W. M. Siu, J. W. Lam, S. N. Willie, P. S. Maxwell, A. Palepu, M. Koether and S. S. Berman, Fresenius' J. Anal. Chem., 1990, 33, 721.

7 J. A. Resing and M. J. Mottl, Anal. Chem., 1992, 64, 2682.

8 V. Porta, C. Sarzanini, E. Mentasti and O. Abollino, Anal. Chim. Acta, 1992, 258, 237.

9 D. Beauchemin and S. S. Berman, Anal. Chem., 1989, 61, 1857.

10 L. Halicy, I. Gavrieli and E. Dorfman, J. Anal. At. Spectrom., 1996, 11, 811 .

11 S. N. Willie, R. E. Sturgeon and S. S. Berman, Anal. Chim. Acta, 1983, 49, 59.

12 J. M. Hill, J. Chromatogr., 1973, 76, 455.

13 C. Fulcher, M. A. Crowell, R. Bayliss, K. B. Holland and J. R. Jezorek, Anal. Chim. Acta, 1981, 129, 29.

14 F. Vernon and H. Eccles, Anal. Chim. Acta, 1973, 63, 403.

15 J. R. Parrish and R. Stevenson, Anal. Chim. Acta, 1974, 70, 189.

16 T. H. Zhang, X. Q. Shan, R. X. Liu and H. X. Tang, Anal. Chem., 1998, 70, 3964.

17 B. W. Zhang, K. Fischer, D. Bieniek and A. Kettrup, React. Polym., 1994, 24, 49 .

18 M. A. Marshall and H. A. Mottola, Anal. Chem., 1985, 57, 729.

19 M. E. Sturgeon, S. S. Berman, S. N. Willie and J. A. H. Desaulniers, Anal. Chem., 1981, 53, 2337.

20 M. Soylak and L. Elci, Int. J. Environ. Anal. Chem., 1997, 66, 51.

21 M. B. Shabani, T. Akagi, H. Shimizu and A. Masuda, Anal. Chem., 1992, 64, 737.

22 Technical No. 8, Dionex Corporation, Sunnyvale, CA, 1994.

23 L. Halicz, I. Gavrieli and E. Dorfman, J. Anal. At. Spectrom., 1996, 11, 811 .

24 D. S. R. Murty and G. Chakrapani, J. Anal. At. Spectrom., 1996, 11, 815 .

Paper 8/09854I 